\title{
Letrōnica
}

\section{O que, afinal, significa afinal?}

\section{What is the meaning of afinal?}

Konrad Szczesniak

Doutor em linguística pela Universidade da Silésia, Polônia Atualmente, trabalha no Instituto da Língua da Silésia. Trabalhou na Universidade do Porto em Portugal e na Educational Testing Service, em Princeton NJ, Estados Unidos. stá interessado na aquisição de fala organização da linguagem no âmbito da Inguistica cognitiva. Estuda a forma, uso sentidos de construçoes gramaticais em inglês, polonês e português. É autor de publicaçoes na área de linguística e vários

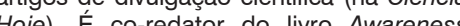
in Action. The Role of Consciousness in (Enguage Acquisition (Editora Springer

konrad.szczesniak@gmail.com
RESUMO: 0 presente estudo concentra-se no desenvolvimento diacrônico, no comportamento e no sentido do marcador discursivo afinal em português. É apresentada uma discussão de dois efeitos semânticos de afinal e uma breve revisão da história de seu uso. A visão dos sentidos concessivos e justificativos convencionalizados proposta na literatura será questionada e será apresentada uma análise alternativa, segundo a qual o marcador afinal se aproveita de suas propriedades formais, preservadas através do principio de persistência, para ativar inferências de foco enfático. PALAVRAS-CHAVE: Marcadores discursivos; Implicatura convencional; Desenvolvimento diacrônico; Persistência.

ABSTRACT: The present study focuses on the diachronic development, behavior and meaning of the discourse marker afinal in Portuguese. A discussion of two semantic effects of afinal will be followed by a brief review of the history of its use. The view of conventionalized concessive and justificative senses proposed in the literature will be questioned here, and an alternative analysis will be offered, under which the marker afinal exploits its formal properties retained through the principle of persistence to trigger inferences of emphatic focus.

KEYWORDS: Discourse markers; Conventional implicature; Diachronic development; Persistence. 


\section{Introdução}

advérbio afinal é exemplo de um marcador discursivo (MD) cuja função consiste em indicar a atitude retórica do falante. Assim, afinal é uma das várias palavras ou expressões que funcionam como mecanismos que indicam a relação entre unidades textuais e/ou entre os interlocutores (PENHAVEL, 2005). É importante sublinhar aqui que MDs são um conjunto bastante divergente de expressões. Risso, Silva e Urbano (2002) afirmam que se trata

de um amplo grupo de elementos de constituição bastante diversificada, envolvendo, no plano verbal, sons não lexicalizados, palavras, locuções e sintagmas mais desenvolvidos, aos quais se pode atribuir homogeneamente a condição de uma categoria pragmática bem consolidada no funcionamento da linguagem. (2002, p. 21)

O MD afinal é uma palavra ortográfica, não obstante, tem suas origens locucionais a partir das expressões a final, ao final e afinal de contas; no presente estudo, afinal é tratado como um item lexical simples. No exemplo abaixo, a ideia introduzida pelo advérbio serve como justificativa da ideia contida na frase anterior.

(1) Claro que ele pode cobrar uma taxa por tais serviços. Afinal, não somos comunistas ${ }^{1}$. (Mario Puzo, O Poderoso Chefão)

Mas tal descrição do sentido de afinal é somente um esboço preliminar. Sentidos exatos de MDs costumam ser difíceis de descrever. Como observou Blakemore, "se se perguntar a um falante nativo o que eles significam, é mais provável que se receba uma descrição ou ilustração de uso do que

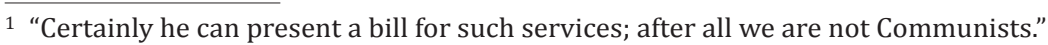

uma paráfrase direta" (BLAKEMORE, 2002, p. 83)². No entanto, o desafio é considerável tanto para falantes comuns quanto para linguistas. Na literatura abundam estudos sobre MDs cujos autores nem sempre estão de acordo no que diz respeito a seu sentido. No caso de after all, equivalente inglês de afinal, há várias análises propostas por Traugott (1997), Blakemore (2002), Brinton (2007), ou Lewis (2006), entre as quais cada uma apresenta uma visão diferente da evolução e do sentido desse marcador.

Infelizmente, as autoras acima referidas não escapam, tal como os falantes nativos mencionados por Blakemore, ao problema de descrição insatisfatória. Isto é, as análises delas são ao mesmo tempo incompletas e imoderadas. Por um lado, os sentidos que elas propõem para o marcador after all não incluem pormenores que, ao meu ver, são caraterísticas importantes dele. Por outro lado, as autoras atribuem sentidos a after all que esse marcador não tem, pois os sentidos em questão não são conteúdo semântico nem significado pragmático convencionalizado. Aqui vou apresentar uma análise alternativa cujas conclusões são válidas tanto para o advérbio português afinal quanto para o marcador inglês after all, e talvez para outros MDs.

Antes de tentar esmiuçar o significado de afinal, primeiro é necessário revisar seus usos típicos e o seu desenvolvimento diacrônico, já que foi através da evolução gramatical que afinal adquiriu suas presentes funções.

\section{Sentidos de afinal}

Distinguem-se três usos principais de afinal. 0 emprego original exprime uma localização temporal literal de um evento. No seguinte exemplo, afinal faz parte de uma locução prepositiva afinal de com o sentido 'no final de' ou 'depois de':

2 "Ask a native speaker what these mean, and you are much more likely to receive a description or illustration of their use than a straightforward paraphrase." (2002, p. 83). 
(2) Aborrecido afinal de trabalho tão monótono e não esperando melhorar de posição em casa de Métayer, passou-se A. Watteau para a officina de Gillot, que pintava com gosto bacchanaes, scenas campestres, ariquinadas... (Leuzinger, Catalogo da Exposicão permanente dos Cimelios, 1885).

Além disso, afinal tem também uma função concessiva que se pode parafrasear como 'não obstante' ou 'apesar de tudo'. No exemplo (3), o fato de o ouvinte estar vivo contradiz suspeitas iniciais que o falante deve ter mantido antes. Segundo Macário Lopes (2008a, p. 8), "sinaliza que a predicação expressa pela frase que o contém anula uma expectativa prévia".

(3) Oh, seu maldoso, afinal está vivo! Está mesmo vivo! Quase perdi a esperança! (Teresa Medeiros, Um Beijo Inesquecível)

Próximo do valor concessivo, distingue-se o chamado uso de "reforço epistêmico", que também sublinha um contraste entre a proposição por ele prefaciada e informação enunciada na frase anterior. Esse valor será descrito em mais pormenor na seção 2 abaixo.

Por último, afinal comumente serve como um marcador justificativo usado para introduzir uma informação que reforça o que foi dito no segmento anterior. No seguinte exemplo, afinal é um advérbio sentencial com escopo sobre a inteira oração anfitriã (host clause).

(4) Fica à vontade, despe-te, não tenhas vergonha; afinal é por isso que estás aqui. (Fernando Correia da Silva, Maresia)

Os usos em (3) e (4) apresentam um problema. Como pode um MD ter adquirido dois sentidos evidentemente opostos? Levinson (1983) admitiu que ainda é preciso realizar estudos apropriados de MDs, mas sua abordagem preliminar consistia em considerar que se trata de implicatura convencional. Segundo Levinson, as funções retóricas de MDs eram inicialmente interpretações apenas implicadas que não faziam parte do sentido deles, mas com a passagem do tempo, foram absorvidas como sentido convencionalizado.

Tal abordagem seria consoante com a ideia, proposta por Traugott, de que os sentidos associados a marcadores teriam sido adquiridos através de fortalecimento pragmático (pragmatic strengthening). Traugott (1988) argumenta que no decurso de gramaticalização, desbotamento semântico (bleaching) não é o único processo que afeta os sentidos de palavras. Durante o chamado "fortalecimento pragmático", palavras gramaticalizadas ganham sentidos pragmáticos. No caso, as funções concessiva e justificativa poderiam ser consideradas como sendo conteúdo estável sem condições de verdade (implicaturas convencionais) do advérbio afinal. Como defende Traugott, "houve um incremento na medida em que as palavras conduzem o ponto de vista do falante sobre a situação ${ }^{3 "}$ (TRAUGOTT, 1988, p. 408).

No entanto, no presente trabalho vou contestar a abordagem de implicatura convencional. Vou tentar apresentar argumentos contra a visão dos sentidos concessivo e justificativo como interpretações estáveis convencionalizadas de afinal. A proposta principal do presente estudo é que o sentido central do advérbio afinal não é a expressão da posição retórica do falante, mas sim uma impressão de ênfase conferida à relação entre duas ideias. Essa ênfase vem do sentido temporal associado com o uso original do advérbio que sofreu o processo de gramaticalização para a forma presente.

Em vez de associar o significado de afinal à implicatura convencionalizada e a fortalecimento pragmático, a presente análise parte da suposição de que a

3 "...there is an increase in the extent to which the words encode the speaker's point of view on the situation." 
ênfase transmitida por meio de afinal é um resíduo do uso temporal. Trata-se de um sentido que permaneceu graças ao princípio de persistência definida por Hopper de seguinte maneira:

Quando uma forma sofre gramaticalização a partir de uma função lexical para uma função gramatical, tanto quanto isto seja gramaticalmente viável, alguns traços de seus sentidos lexicais originais tendem a continuar, e detalhes da sua história lexical podem se refletir no condicionamento da sua distribuição gramatical. ${ }^{4}$ (HOOPER, 1991, p. 22)

Vale sublinhar o trecho "tanto quanto isto seja gramaticalmente viável" afinal é uma palavra gramatical; por isso, sua capacidade de reter significado é limitada. MDs são formas de classes fechadas e, sendo assim, seus sentidos devem ser congruentes com a capacidade semântica de palavras gramaticais. Tradicionalmente, costumou-se considerar que formas gramaticais têm um conteúdo semântico geral, minimal e esquemático. Por exemplo, Evans (2011) contrasta formas de classes abertas e fechadas e argumenta que palavras lexicais (classes abertas) têm "conteúdo semântico rico" e as palavras gramaticais (classes fechadas) apresentam "conteúdo semântico esquemático". De maneira similar, Murphy explica que

as classes fechadas contêm palavras funcionais ou palavras gramaticais; isto é, palavras que têm funções gramaticais em vez de sentidos ricos. ... As classes fechadas representam um grupo mais restrito de sentidos, e os sentidos de palavras das classes fechadas costumam ser menos detalhadas e menos referencial do que palavras das classes abertas. ${ }^{5}$ (MURPHY, 2010, p. 15)

\footnotetext{
4 "When a form undergoes grammaticalization from a lexical to a grammatical function, so long as it is grammatically viable, some traces of its original lexical meanings tend to adhere to it, and details of its lexical history may be reflected in constraints on its grammatical distribution." (HOOPER, 1991, p. 22). 5 "the closed classes contain function words or grammatical words; that is, words that have grammatical functions rather than rich meanings. (...) The closed classes represent a more restricted range of meanings, and the meanings of closed-class words tend to be less detailed and less referential than open-class words." (MURPHY, 2010, p. 15).
}

É nesse espírito que foram analisados os sentidos de várias construções gramaticais. Em um estudo de construções em português e inglês, Szcześniak (2014) sublinha "um grau de austeridade semântica de formas funcionais associadas com a sintaxe" (SZCZEŚNIAK, 2014, p. 313-314). É assim também que vou tratar do sentido do marcador afinal.

\section{Desenvolvimento diacrônico}

O marcador afinal parece ter seguido o mesmo rumo de evolução que seu equivalente inglês after all, analisado por Traugott (1997) e Lewis (2007). As duas autoras distinguiram quatro etapas históricas principais, que são paralelas às identificadas por Macário Lopes (2008a) e Vicente (2009) no português.

\subsection{Uso temporal}

O uso original tem três grafias a final, ao final e afinal, das quais a primeira é antiga e hoje não utilizada (de Queiroz Piacentini, 2012, p. 107). Segundo Macário Lopes (2008a), afinal era "ordenador temporal, sinalizando que a situação descrita pela proposição que tipicamente introduz é a última de uma sequência" (p. 15). Esse uso exprimia uma sequência temporal de eventos, onde afinal significava 'no final' e aparecia seguido de um sintagma preposicional que especificava um período de tempo. No exemplo (5), a última ocorrência (a morte) tem lugar no fim de "larga edade". Nessa etapa de uso do advérbio afinal, ainda não há sinais claros de concessão nem justificativa.

(5) Em França, teve depois o posto de marechal d'aquella corôa, a quem serviu até que, por não abraçar a religião catholica romana, quando Luiz xiv revogou o edicto de Nantes em 1685, mandando despejar dos deus reinos os Huguenotes, voltou a Portugal em 1688, donde passou ao serviço do 
eleitor de Brandebourg, e depois ao serviço d'el-rei Guilherme III da GranBretanha, morrendo afinal de larga edade no anno de 1690, vencendo na Irlanda a batalha de Boyne. (Simão José da Luz Soriano, Historia de reinado de el-rei D. José e da administração do marquez de Pombal, 1867)

\subsection{Uso concessivo}

O sentido concessivo é uma continuação do uso temporal. O substantivo que aparece depois do advérbio descreve um fato que impedia a ocorrência que teve lugar, apesar das dificuldades, obstáculos ou quaisquer contraindicações. Embora o fato seja um ponto situado no tempo, mais essencial do que a relação temporal é o aparente contraste lógico entre as ideias mencionadas na oração (triunfo apesar dos obstáculos).

(6) É verdade que, depois de inveterado o mal, torna-se o remedio mais arduo, porém a firmeza temperada com a prudencia, e dirigida por indefesa perseverança, ha de triumphar a final de todos os obstaculos. (Imprensa da Universidade, $O$ Instituto, Coimbra 1856)

Nesse sentido, Moura Neves (2000, p. 864) afirma que construções concessivas e construções adversativas têm sido inseridas "entre as conexões contrastivas, cujo significado básico é 'contrário à expectativa', um significado que se origina não apenas do conteúdo que está sendo dito, mas, ainda, do processo comunicativo e da relação falante-ouvinte".

\subsection{Uso epistêmico}

Tal como after all em inglês, afinal passou a ser usado com o valor de "reforço epistêmico". Segundo Macário Lopes (2008a), esse uso de afinal "sinaliza e sublinha a plausibilidade epistémica da proposição hospedeira, apresentando-a como algo que é conhecimento partilhado, comummente aceite." (MACÁRIO LOPES, 2008a, p. 11-12). No exemplo a seguir, a ideia do destino de Heitor, fadado a morrer, está em oposição aos vaticínios favoráveis descritos nas frases anteriores. A contraexpectativa serve para enfatizar a verdade da proposição assim enunciada.

(7) Heitor era filho de Priamo e Hecuba, e segundo dos heroicos vultos homericos. Havia o oraculo vaticinado que, enquanto elle vivesse, o imperio de Priamo resistiria aos ataques dos gregos, e por isso 31 dos mais valentes inimigos morreram ás suas mãos, pertendendo derrubá-lo. Mas afinal a sua sorte acha-se ja indicada na nota sobre Achilles. (Ovis, Os Amores, 1858)

\subsection{Uso justificativo}

Mais tarde, surge o uso justificativo ilustrado nos exemplos (8a-b). Segundo Vicente (2009) que utiliza o termo "operador argumentativo", o uso justificativo "pode ser parafraseado por 'pois', o que denota seu caráter explicativo, também validando um raciocínio conclusivo" (2009, p. 74). Esse uso é mais afastado do valor temporal, já que o evento descrito na oração não aparece necessariamente no fim de uma sequência temporal. No exemplo abaixo, a libertação do homem ocorre antes, não depois dos outros acontecimentos relacionados na descrição. 0 uso de afinal sugere que o evento (libertação) é um argumento a favor de abandonar as acusações.

(8) a. Era o que elle desejava conseguir: fazer com que a condessa de Refoyos e a filha abandonassem a attitude de rés ou de victimas do crime d'um homem que, afinal de tudo, fora solto por falta de provas! (Manoel Caldas Cordeiro, Anciosos, 1895)

b. Estas praticas que alguns julgaram precizo consentir para não affrontar tanto os usos inveterados e queridos d'aquelles povos, nunca 
foram toleradas pela Curia Romana, e afinal de todo as condemnou a bulla do papa Bento xiv, da qual data certo juramento exigido aos jesuitas das missões, a que o padre Loureiro allude mais de uma vez em suas notas, mas que parece elle não fora obrigado a prestar. (Typographia da Academia, Memorias da Academia Real das Sciencias de Lisboa, 1872)

No valor justificativo de afinal, a ideia temporal deu lugar a uma relação retórica na qual se fornece um argumento forte a favor de uma ideia menos certa. Nas palavras de Macário Lopes (2008a),

afinal codifica a instrução de que o segmento que introduz é um argumento forte que explica/justifica a proposição expressa no primeiro segmento da construção; ao mesmo tempo, ao usar afinal o falante sugere que o interlocutor aceitará facilmente como argumento a proposição que afinal introduz e isto porque tal argumento configura um facto ou uma assunção consensual, algo que não oferece dúvidas nem suscita contestação. (MACÁRIO LOPES, 2008a, p. 13)

É importante ressaltar que as etapas descritas acima coincidem com a evolução do marcador after all em inglês (TRAUGOTT, 1997). As semelhanças entre o português e inglês podem parecer impressionantes, talvez implausíveis. Como podem ter surgido usos tão parecidos em duas línguas diferentes, quase ao mesmo tempo? Certamente, houve algumas diferenças nos respectivos desenvolvimentos diacrônicos no português e inglês. Não argumento que a evolução de afinal seguisse, passo por passo, exatamente o mesmo caminho que after all (com idênticas percentagens de usos). No entanto, parece que existe uma lógica em comum entre a ideia de finalidade e os usos concessivo, epistêmico e justificativo, e essa lógica é partilhada por várias línguas na gramaticalização de MDs. Isso é evidente na seguinte amostra informal de equivalentes de afinal (com o sentido justificativo) em várias línguas, das quais todas fazem uma referência ou ao substantivo "fim" (9a) ou a equivalentes da locução preposicional "depois de" (9b).

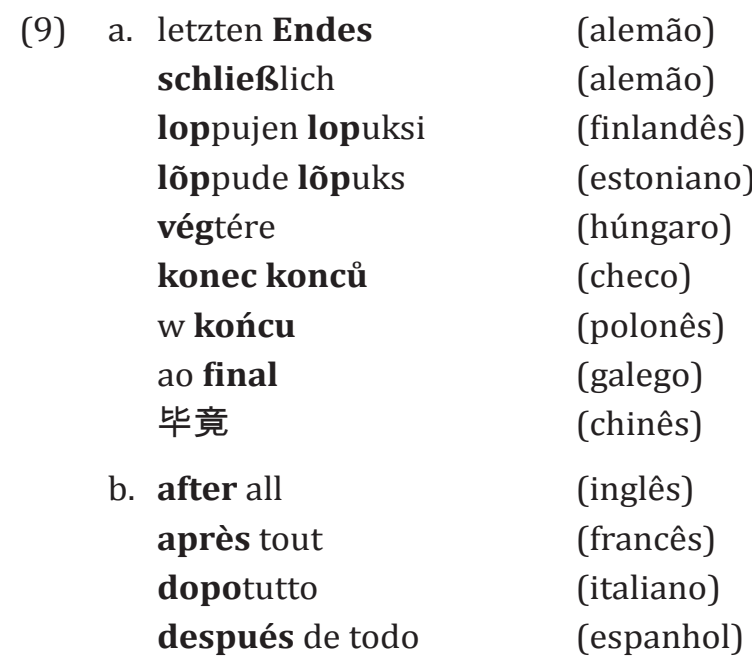

Tais semelhanças entre várias línguas são consistentes com a ideia de que convergências ocorrem apesar de diferenças evidentes. Bybee (2010) afirma que:

Línguas diferem uma da outra apesar de serem evidentemente moldadas pelos mesmos príncipios; construções comparáveis em diferentes línguas servem funções semelhantes e são baseadas em princípios semelhantes, porém diferem uma da outra de modos particulares; ... as línguas mudam ao longo do tempo, mas de modos bastante regulares. ${ }^{6}$ (BYBEE, 2010, p. 1)

6 ...languages differ from one another while still being patently shaped by the same principles; comparable constructions in different languages serve similar functions and are based on similar principles, yet differ from one another in specifiable ways; (...) languages change over time, but in fairly regular ways. (BYBEE, 2010, p. 1) 


\section{Ilusão de convencionalização}

Apesar de algumas diferenças quanto ao processo exato de evolução, Lewis e Traugott concordam que os sentidos concessivo e justificativo surgiram como consequência do uso temporal e que se tornaram sentidos convencionalizados do marcador afinal. Eu gostaria de propor uma análise distinta, segundo a qual os sentidos concessivo e justificativo não fazem parte do sentido de afinal, mas sim são interpretações feitas com base nas informações contidas no discurso. Na próxima seção do trabalho, vou me concentrar nas razões pelas quais os sentidos em questão deveriam ser considerados como inferências contextuais, e não sentidos próprios de afinal.

Em primeiro lugar, é importante considerar que as atitudes retóricas do falante, quer sejam concessivas quer justificativas ou outras, são muitas vezes bastante transparentes mesmo sem a mediação de marcadores. Como argumenta Łyda (2007), “Concessão (... ) pode ter seus marcadores visíveis como no entanto e mas, aliás, com mais frequência os marcadores são ausentes e, o que é mais importante ainda, com a mesma frequência as mesmas expressões não funcionam como marcadores de Concessão" (p. 16) ${ }^{7}$. Nos exemplos (10a-b), o próposito da oração sublinhada seria claro até mesmo na ausência de um marcador. Em (10a), a primeira frase introduz uma asserção que é depois reforçada através de uma ideia evidente que não se pode descartar. Tal organização sugere de forma bastante clara que a segunda frase serve como justificativa. Esse padrão foi resumido por Lewis da seguinte forma: "a natureza da relação explica o condicionamento de tipos de segmentos que podem ser relacionados por um concreto marcador:

\footnotetext{
"Concession ... may have its surface markers like although and but, yet most frequently the markers are absent and even more importantly, equally often the same expressions do not function as markers of Concession." (ŁYDA, 2007, p. 16).
}

no caso, uma ideia relativamente incerta tem que ser seguida de uma ideia mais certa." (2006, p. 10) ${ }^{8}$.

(10) a. Compre esse carro. Você sempre o quis ter!

b. A face de meu irmão permanece sem expressão alguma. Talvez ele realmente não esteja me reconhecendo.

Em (10b), uma observação feita na primeira frase leva a uma conclusão tímida que pressupõe uma antítese assim negada. Na situação descrita aqui, o falante supõe que, contra as expectativas de ser reconhecido por seu irmão (antítese), o irmão é capaz de não o reconhecer (conclusão con(essiva) ${ }^{9}$.

O sentido justificativo (10a) e o concessivo (10b) são evidentes o suficiente para serem deduzidos somente a partir dos significados das elocuções; não é necessário marcar esses sensos por meio de afinal, que pode aparecer só para ênfase adicional.

Mais um argumento contra a convencionalização dos dois sentidos em questão é o problema de antonímia inerente. Se afinal de fato incorporou os sentidos em questão, são assim convencionalizados dentro de um único item lexical dois sentidos mutuamente opostos. Segundo Blakemore (2002), um marcador pode exercer efeito cognitivo satisfazendo três condições:

8 "The nature of the relation thus accounts for constraints on the types of segments that can be related by a particular marker: in this case, a relatively uncertain idea must be followed by a more certain one." (LEWIS, 2006, p. 10)

9 Tais antíteses contrafatuais são normalmente ativadas por meio de formas negativas (TALMY, 2000), segundo o qual "uma oração sintacticamente negativa (por exemplo, Não fui para festa do João na noite passada) abertamente aponta algo que não teve lugar, mas tende a evocar uma imagem de um evento positivo não realizado correspondente ao negativo." (p. 291) ("a syntactically negative clause (e.g., I didn't go to John's party last night) overtly names something that did not take place but tends to evoke consideration of the corresponding unrealized positive event" (TALMY,
2000, p. 291)). 
(i) ele permite derivação de implicaturas contextuais; ou

(ii) ele fortalece uma suposição existente; ou

(iii) ele leva a contradição e eliminação de uma suposição existente. (BLAKEMORE, 2002, p. 95) ${ }^{10}$

Tal antonímia é rara, se não mesmo inexistente. Por exemplo, a mera possibilidade de ambiguidade levou alguns falantes a questionar a forma inflamável e propor a forma flamável como alternativa. Segundo eles, não é claro se o sentido é 'que pode pegar fogo facilmente' ou a negação desse sentido. Embora tais preocupações sejam dispensadas em consultórios linguísticos como Ciberdúvidas ou Sobre Palavras ${ }^{11}$, trata-se de uma reação natural de falantes desconfiados de uma palavra com dois sentidos contraditórios. Do mesmo modo, é pouco provável que afinal tenha dois significados opostos. É mais razoável supor que esse marcador somente sinaliza uma ligação retórica entre duas ideias, enquanto os sentidos de concessão e justificativa são derivadas do contexto.

\section{Sentido de afinal}

Considerando esses problemas, vamos assumir que pelo menos algumas partes do significado de afinal (concessão ou justificativa) não passam de inferências contextuais que surgem em determinadas situações, dependendo do conteúdo das frases. No entanto, além dessas, existem ainda outras inferências que dependem também das propriedades formais do marcador. Isto é, o advérbio afinal ainda integra em si o substantivo final que em termos

${ }^{10}$ (i) it allows the derivation of contextual implications; or

(ii) it strengthens an existing assumption; or

(iii) it leads to the contradiction and elimination of an existing assumption." (Blakemore 2002: 95)

${ }^{11}$ Ver Ciberdúvidas, disponível em <http://www.ciberduvidas.com/pergunta.php?id=15396> e Sobre Palavras, disponível em <http://veja.abril.com.br/blog/sobre-palavras/consultorio/por-que-o-inflamavelnao-e-so-flamavel/>. semânticos não pode ser um trecho completamente arbitrário. A forma afinal pode já não evocar na mente dos falantes uma associação imediata consciente com o "fim", mas indiretamente utiliza um traço semântico do substantivo final. Em outras palavras, apesar de ter perdido, no processo de desbotamento semântico, uma referência direta a um fim, afinal sustenta, graças ao princípio de persistência, uma "memória" latente de uma sequência temporal e sua última parte.

Eis um possível mecanismo de como isso pode ocorrer. Embora afinal apareça em usos concessivos sem locuções preposicionais, como de todos os obstáculos do exemplo (6) acima, continua ainda a consciência tácita de que final, sendo um substantivo relacional, necessita complementação, quer ela seja realizada, quer seja implícita. Assim, mesmo que afinal seja usado individualmente, é possível recuperar o complemento preposicional.

Esse seria um mecanismo sintático, mas ele teria consequências para a interpretação semântica de afinal. O complemento deduzido assim alude a uma série de acontecimentos que precediam a constatação feita. Por exemplo, na seguinte frase afinal parece fazer referência a acontecimentos que poderiam ser resumidos na locução preposicional "de todas as aparências falsas/mentiras/trapaças etc." que a constatação acaba por desmascarar.

(11) Então, afinal, foi você quem roubou o dinheiro!

Neste momento, é preciso apontar que a referência a eventos é um efeito semântico plausível para uma palavra gramatical. Sentidos que têm a ver com elementos temporais encontram-se frequentemente em formas de classes fechadas, tais como sufixos de tempo passado ou construções gramaticais de aspecto temporal.

A capacidade de aludir a uma sequência de acontecimentos precedentes tem uma consequência especial. Os acontecimentos em questão introduzem 
uma antítese elaborada, um pano de fundo contextual, face ao qual a constatação ganha maior ênfase. No caso do exemplo (11), a descoberta do culpado vem como uma surpresa abrupta, especialmente à luz da antítese de que o culpado, por vários motivos, estava fora de suspeita.

O mesmo se dá com o uso justificativo, que parece introduzir ênfase no argumento apresentado na frase. Esse efeito pode escapar à atenção em usos típicos, especialmente porque muitas vezes afinal pode ser substituído por outros marcadores justificativos, causando a impressão de que não há nada de peculiar em afinal que o distinguisse dos outros marcadores. Por exemplo, em muitas situações afinal e porque exercem a mesma função:

(12) a. Após sair do hospital, ficou no abrigo aos cuidados dos colegas, afinal ela não tinha família. (Ironita Mota, Vidas E Destinos)

b. Após sair do hospital, ficou no abrigo aos cuidados dos colegas, porque ela não tinha família.

No entanto, sendo mais enfático, afinal só pode ser usado para introduzir uma informação que seja definitiva. Enquanto porque pode introduzir ideias incertas ou até mesmo especulações (13a), afinal só serve para introduzir asserções sólidas. É claramente anômalo seu uso sequencial com várias hipóteses hesitantes (13b).

(13) a. "Nesse momento fazem seis meses, seis dias e seis horas exatos que estou esperando o telefonema de Ana. Talvez ela não ligou porque não tinha telefone na caverna, talvez porque ela não quis, talvez porque fui idiota e deveria ter pego o número dela..." (Delson Borges, PÔ Emas E Textículos)

b. ... (ainda) estou esperando o telefonema de Ana. Talvez *afinal não tinha telefone na caverna, talvez *afinal ela não quis, talvez *afinal fui idiota e deveria ter pego o número dela
Existem provas de que o advérbio afinal é uma versão comprimida de locuções temporais de forma [afinal de suBstantivo]. Uma delas, afinal de contas, persistiu em uso até hoje. É claro que, originalmente, o substantivo contas tinha um sentido mais literal e significava 'cálculos' e 'decisões'; os primeiros usos de afinal de contas sublinhavam que a ideia transmitida na oração vinha como resultado de um processo de cálculos, como no seguinte exemplo.

(14) A final de contas foi a proposta derrotada por uma maioria de perto de tres contra um, e passou a camara a constituir-se em commissão a fim de discutir as clausulas do projecto, e, depois de prolongada discussão, foram adoptados os cinco primeiros paragraphos. (Discussão da Reforma do Estado Servil, 1871).

Já que um cálculo se pode entender de forma mais abrangente, incluindo 'cálculos mentais', a expressão passou a ser utilizada em quaisquer outras situações envolvendo avaliação ou meditação. Assim, hoje afinal de contas é um fóssil vivo. É um precursor do marcador abreviado afinal que coexiste a seu lado, e as duas formas são hoje sinônimas, o que é evidente em traduções da famosa frase de Scarlett O'Hara "After all, tomorrow is another day":

(15) a. Afinal, amanhã é outro dia.

b. Afinal de contas, amanhã é outro dia.

Para nossos propósitos, afinal de contas tem duas funções. Primeiro, indica o origem da forma afinal. Além disso, permite aproximar o sentido de afinal e mostrar como ele difere de outras expressões concessivas e justificativas, por sinalizar uma relação retórica enfatizada. No caso de concessão, afinal transmite a impressão de que o acontecimento mencionado ocorre contra todas as probabilidades. Por outro lado, no que se refere ao uso justificativo, o marcador expressa a convicção de que o fato que ele introduz 
é o argumento mais adequado e relevante para fundamentar uma asserção no discurso anterior.

São efeitos naturalmente associados com o conceito do tempo e fim. Existe uma lógica metáforica segundo a qual o fim de um processo equivale a uma conclusão premeditada. Essa ligação (entre o conceito de decisão cuidadosa e a ideia do fim) parece evidente dado de que a própria palavra conclusão tem uma etimologia temporal; vem da raiz latina cludere/claudere com o sentido 'fechar, acabar'.

A lógica temporal também está presente em outros marcadores com funções semelhantes. De fato, os empregos retóricos podem se juntar a quaisquer outras expressões que transmitem o último passo de um processo. Tal foi o caso de enfim, que sofreu mudanças de gramaticalização mais cedo do que afinal. O sentido retórico de enfim já foi registrado no século XVIII. No Novo Diccionario das Linguas Portugueza e Franceza, a locução em fim aparece na entrada finalmente, definida como 'em conclusão' (MARQUES, 1764, p. 295).

Mas, originalmente, o marcador enfim (escrito separadamente) teve empregos temporais que coexistiam com os retóricos. Segundo Macário Lopes (2008b), usos discursivos de enfim vêm do uso temporal "comutável por finalmente, por fim, e também por ultimo" (p. 63). É importante observar que a mesma situação se dava em português (16) e espanhol (17):

(16) Em fim outra explosão annuciou a transformação da cornucopia em tres radiosas estrellas, que descerão lentamente para a terra, junto á qual se desfizerão e desapparecerão. (Archivo Popular, 1839)

(17) ... auemos de atender a la gloria de los siglos venidores que es eterna en las regiones etereas y celestes, que à la vanidad de la fama, que en este presente y acabable siglo se alcança, la qual fama por mucho que dure, en fin se ha de acabar con el mesmo mundo, que tiene su fin (Miguel de Cervantes Saavedra, Segunda parte del ingenioso cauallero don Quixote de la Mancha, 1615, p. 68)

\section{Conclusões}

O sentido do advérbio afinal é restringido por sua natureza gramatical, e o sentido proposto aqui é consoante com sentidos encontrados em palavras gramaticais. No entanto, até mesmo dentro dos constrangimentos gramaticais, o marcador afinal é capaz de apresentar efeitos bastante complexos e interessantes. Enquanto sua função retórica (de confirmação ou desmentido) exata permanece em aberto, flexível o suficiente para se realizar em um determinado contexto, afinal tem o potencial de pressupor a existência de fatos relevantes que servem como um pano de fundo para realçar o peso da ideia assim introduzida. Embora esse potencial resulte de vestígios sutis preservados de acordo com o princípio de persistência, seu efeito em forma de inferências contextuais é forte o suficiente para distinguir afinal de vários marcadores (tais como porque, já que, pois) como sendo um marcador enfático.

As restrições devidas à natureza gramatical desse marcador discursivo são pelo menos em parte responsáveis pelas semelhanças entre o desenvolvimento de afinal no português e seus equivalentes em outras línguas, como se pode verificar nos exemplos apresentados no fim da seção 2 . A gramática impõe limites quanto aos tipos e número de possíveis sentidos, estreitando assim o caminho pelo qual pode seguir a evolução de uma forma gramatical, como no caso do marcador discursivo afinal.

\section{Referências}

BLAKEMORE, D. Relevance and Linguistic Meaning. The semantics and pragmatics of discourse markers. Cambridge: Cambridge University Press, 2002. http://dx.doi. org/10.1017/CB09780511486456

BRINTON, L. J. Rise of the adverbial conjunctions \{any, each, every\} time. In: Connectives in the History of English. Amsterdam: John Benjamins, 2007. p. 77-96. http://dx.doi. org/10.1075/cilt.283.06bri 
BYBEE, J. Language, Usage and Cognition. Cambridge: Cambridge University Press, 2010. http://dx.doi.org/10.1017/CB09780511750526

DE QUEIROZ PIACENTINI, M. T. Não Tropece na Língua: Lições e curiosidades do português brasileiro. Curitiba: Bonijuris, 2012.

EVANS, V. Language and cognition: The view from cognitive linguistics. In: Language \& Bilingual Cognition. New York: Psychology Press, pp. 69-107, 2011.

HOPPER, P. J. On some principles of grammaticization. In: E. C. Traugott \& B. Heine, eds. Approaches to Grammaticalization, Vol. I. Amsterdam: John Benjamins, 1991. p. 17-35. http://dx.doi.org/10.1075/tsl.19.1.04hop

LEVINSON, S. C. Pragmatics. Cambridge: Cambridge University Press, 1983.

LEWIS, D. M. Discourse markers in English: a discourse-pragmatic view. In: Approaches to Discourse Particles. Amsterdam: Elsevier, 2006. p. 43-60.

LEWIS, D. M. From temporal to contrastive and causal: The emergence of connective after all. In: Connectives as Discourse Landmarks. Amsterdam: John Benjamins, 2007. p. 89-102. http://dx.doi.org/10.1075/pbns.161.09lew

ŁYDA, A. Concessive relation in spoken discourse: A study into academic spoken English. Katowice: University of Silesia, 2007.

MACÁRIO LOPES, A. C. Afinal: elementos para uma análise semântico-pragmática. Revista Linguística, jun., v. 4, n. 1, p. 1-19, 2008a.

MACÁRIO LOPES, A. C. Enfim. Estudos Linguísticos, v. 2, p. 61-76, 2008b.

MARQUES, J. Novo Diccionario das Linguas Portugueza e Franceza. Lisboa: Officina Patriarcal de Francisco Luiz Ameno, 1974.

MOURA NEVES, M. H. d. Gramática de usos do português. São Paulo: Editora UNESP, 2000.

MURPHY, L. M. Lexical Meaning. Cambridge: University Press, 2010. http://dx.doi. org/10.1017/CB09780511780684

PENHAVEL, E. Sobre as funções dos marcadores discursivos. Estudos Lingüísticos, v. 34, p. 1296-1301, 2005

RISSO, M. S.; SILVA, G. M. d. O. e.; URBANO, H. Marcadores discursivos: traços definidores. Em: Gramática do português falado. v. VI. Desenvolvimentos. São Paulo: Unicamp, 2002. p. 21-103.
SZCZEŚNIAK, K. Quanto significam as construções? Sentidos de formas de classes fechadas. Cadernos de Letras UFF, Anáfora e correferência: temas, teorias e métodos, v. 49, p. 309-326, 2014.

TALMY, L. Toward A Cognitive Semantics. Concept Structuring Systems. Volume I, Cambridge, MA: MIT Press, 2000.

TRAUGOTT, E. C. Pragmatic Strengthening and Grammaticalization. Proceedings of the Fourteenth Annual Meeting of the Berkeley Linguistics Society, p. 406-416, 1988.

TRAUGOTT, E. C. The Discourse Connective after all: A Historical Pragmatic Account, Paris: Paper presented at ICL, Paris, July, 1997.

VICENTE, R. B. Mudança gramatical da palavra afinal e sua gramaticalização num contraste entre variedades linguísticas: português do Brasil e de Portugal. São Paulo: Universidade de São Paulo, 2009.

Recebido em 20 de dezembro de 2014. Aceito em 15 de maio de 2015. 